\title{
Recent Methodology in Ginseng Analysis
}

\author{
Seung-Hoon Baek ${ }^{1}$, Ok-Nam Bae ${ }^{2}$, and Jeong Hill Park ${ }^{3 *}$ \\ ${ }^{1}$ College of Pharmacy, Ajou University, Suwon 443-749, Korea \\ ${ }^{2}$ College of Pharmacy, Hanyang University, Ansan 426-791, Korea \\ ${ }^{3}$ College of Pharmacy and Research Institute of Pharmaceutical Science, Seoul National University, Seoul 151-742, Korea
}

As much as the popularity of ginseng in herbal prescriptions or remedies, ginseng has become the focus of research in many scientific fields. Analytical methodologies for ginseng, referred to as ginseng analysis hereafter, have been developed for bioactive component discovery, phytochemical profiling, quality control, and pharmacokinetic studies. This review summarizes the most recent advances in ginseng analysis in the past half-decade including emerging techniques and analytical trends. Ginseng analysis includes all of the leading analytical tools and serves as a representative model for the analytical research of herbal medicines.

Keywords: Panax ginseng, Ginseng analysis, Mass spectrometry, Metabolomics, Genetic marker, Immunoassay

\section{INTRODUCTION}

Recently, traditional herbal medicines have been gaining attention as the therapeutic candidates for many chronic or degenerative diseases caused by multifactorial causes in modern society $[1,2]$. Single or simple mixtures of active compounds are no longer considered to be the best therapeutic choices for treating these diseases. Formulations of natural medicines composed of diverse phytochemicals may be potential alternatives in preventing or overcoming incurable diseases through their ability to modulate multiple targets, enhance self-healing and adaptogenic capacity as described in the ethnopharmacological literature [3]. Low toxicity and reliable efficacy in humans that has been verified through a long medicinal history are other advantages of natural medicines that are encouraging the development of herbal medicines in modern therapeutics. However, the main problem in natural medicine development is quality control, as the quality can be influenced by many factors, including differences in cultivation methods, environment, and the

(c) This is an Open Access article distributed under the terms of the Creative Commons Attribution Non-Commercial License (http://creativecommons.org/licenses/by-nc/3.0/) which permits unrestricted non-commercial use, distribution, and reproduction in any medium, provided the original work is properly cited. genetic background of plant species. Validated analytical methods for herbal medicines are important not only to establish drug standards, including species authentication and quality assessment, but also to understand drug targets and pharmacokinetic properties [4,5]. Analytical methods will therefore play an essential role in the discovery of innovative herbal medicine therapeutics.

Ginseng is a best-selling herbal medicine and has been a top-ranked subject of many fields of scientific research worldwide. The medicinal history of ginseng can be traced back over approximately 2,000 years to one of the first descriptions in ancient Oriental medical literature [6]. The English name 'ginseng' is derived from Chinese word meaning man-shaped root. Owing to this shape, ginseng is considered sacred in oriental medicine. Together with various beneficial activities, ginseng is known as a noble, miraculous medicine and is prescribed to treat many symptoms. More than 5,000 research papers have been published in authoritative scientific journals on the

Received 21 Dec. 2011, Revised 25 Jan. 2012, Accepted 25 Jan. 2012

*Corresponding author

E-mail: hillpark@snu.ac.kr

Tel: +82-2-880-7857, Fax: +82-2-874-8928 
secrets of ginseng, which have traditionally been transmitted by word-of-mouth. Ginseng research must draw on aspects of natural product chemistry, pharmacognosy, pharmacology, plant bioengineering, and analytical sciences. With particular respect to analytical methodologies of ginseng, many researchers have developed methods (in terms of metabolomics) of single or multiple phytochemical analyses using sophisticated chromatographic tools as well as total extract or plant material analyses using both spectroscopic techniques and statistics [6,7]. The 'ginseng analysis' should be the professional term used to refer to analytical approaches for ginseng, and is a representative model for other natural medicines.

In this review, we summarize the advances in ginseng analysis over the past 5 years with a brief overview on the background of ginseng, such as the botanical species, types of ginseng, chemical constituents, and pharmacology. The various analytical methods are the main focus, including separation-based single/multiple phytochemical analysis, whole mixture analysis without separation, genetic techniques, and immunoassays. This review will provide a comprehensive overview of the current trends in ginseng analysis and give new insights into the future of analytical techniques for natural medicines.

\section{BOTANICAL SPECIES OF GINSENG}

Traditionally, 'ginseng' refers to the root of Panax ginseng. However, plants belonging to the genus Panax have recently also been denoted as 'ginseng'. Ginseng is also named after its native habitat, such as Korean, Chinese, American, and Japanese ginseng. Of these, ginseng (Korea) has been studied the most intensively. It is $P$. ginseng Meyer native to Korea and is the most well-known ginseng with potent pharmacological efficacies [8]. Chinese ginseng is $P$. notoginseng (Burk.) F. H. Chen native to China. American ginseng is $P$. quinquefolius L. native to North America, including Canada and United States. These 3 species are widely used as a functional food and in traditional medicine. In addition, P. japonicus Meyer (Japanese ginseng), P. pseudoginseng subspecies Himalacius (Himalayan ginseng), P. trifolius (dwarf ginseng), and $P$. vietnamensis Ha et Grushv. (Vietnamese ginseng) are lesser known Panax species [7]. However, adaptogenic plants in some counties are called ginseng owing to their ginsenglike effects. Because these plants are not the Panax species, they are not considered to be true ginseng. These ginseng alternatives include, among others, Siberian ginseng (Eleutherococcus senticosus), Indian ginseng (Withania somnifera), and Brazilian ginseng (Pfaffia paniculata).

\section{TYPES OF GINSENG PREPARATIONS}

Ancient pharmacists created transformed herbal medicines through steaming, roasting, or fermenting. Processing leads to changes in the component phytochemicals, thereby expanding the chemical diversity and bolstering the overall efficacies [9]. Processing is now gaining interest in an effort to create new medicinal recourses having diverse chemical pools, and many new advanced techniques are currently being examined and applied.

Traditionally, ginseng refers to the root, and the other parts of ginseng, such as the leaves and berries, are rarely used. The ginseng preparations described below follow this traditional notion. Fresh ginseng refers to immediate harvest without any additional processing. Because of problems during storage or circulation, in most cases, fresh ginseng is turned into white or red ginseng. White ginseng refers to dried ginseng, while red ginseng is the transformed ginseng created by traditional processing with successive steaming and drying. Our research group developed a new processed ginseng (called sun ginseng) from $P$. ginseng through steaming under optimized high temperature and pressure conditions. Sun ginseng contains increased levels of biologically active, less polar ginsenosides and enhanced pharmacological activities compared to those of white and red ginseng [10,11]. This processing method has also been applied to different Panax species and other natural medicines [12]. Other types of processed ginseng have been developed using modified steaming, explosive puffing, or fermentation with specific microorganisms, such as intestinal microbial flora. Black ginseng is prepared by repeated cycles of atmospheric steaming and sun-drying [13]. Puffed ginseng is prepared by applying an optimized puffing pressure and residual moisture content in ginseng [14]. Fermentation with intestinal microbial flora leads to structural modification of the ginsenosides. Compound $\mathrm{K}$, the intestinal metabolite of ginsenoside, is a representative bioengineered ginsenoside that shows potent anti-cancer effects [15]. New types of processed ginseng preparations will be developed in the future [16]. Aside from the ginseng preparations that have originated from cultivated ginseng plants, wild mountain ginseng grown in the highlands is also available.

\section{PHARMACOLOGICAL EFFICACIES AND CHEMICAL CONSTITUENTS OF GINSENG}

As the genus name Panax, meaning 'cure all' in Greek, implies, ginseng has been referred as a panacea and pre- 


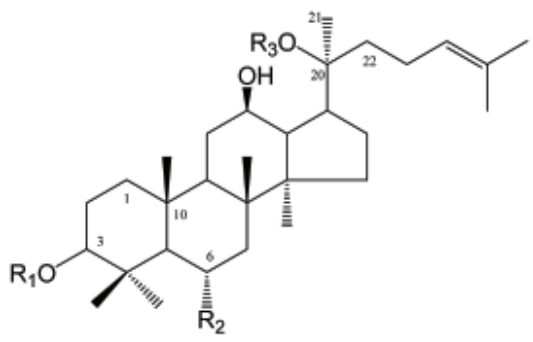

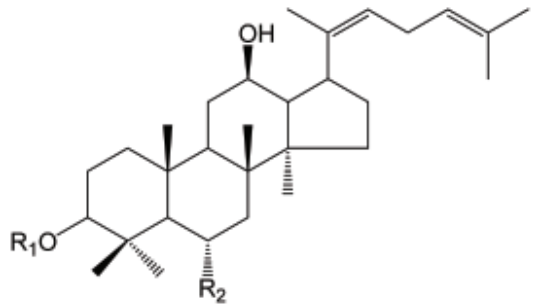

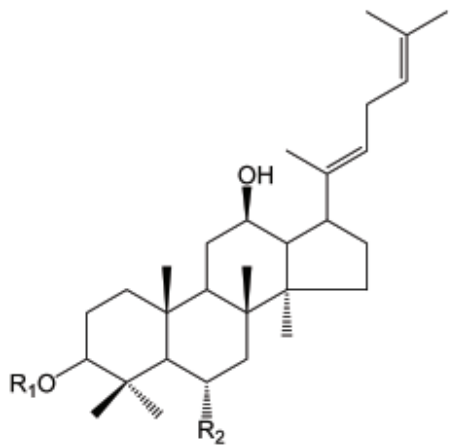

\section{PPD}

Ginsenoside-Ra,

Ginsenoside- $\mathrm{Ra}_{2}$

Ginsenoside- $\mathrm{Ra}_{3}$

Ginsenoside-Rb

Ginsenoside-R $\mathrm{b}_{2}$

Ginsenoside- $\mathrm{Rb}_{3}$

Ginsenoside-Rc

Ginsenoside-Rd

Ginsenoside- $\mathrm{Rg}_{3}(20-\mathrm{R}, \mathrm{S})$

Ginsenoside- $\mathrm{Rh}_{2}(20-\mathrm{R}, \mathrm{S})$

Ginsenoside-Rs,

Ginsenoside-Rs

Ginsenoside-Rs

PPT

Ginsenoside-Re

Ginsenoside-Rf

Ginsenoside-Rg

Ginsenoside- $\mathrm{Rg}_{2}(20-\mathrm{R}, \mathrm{S})$

Ginsenoside-Rh, (20-R,S)

DHPPD-I

DHPPT-I

Ginsenoside-Rg

Ginsenoside-Rk

Ginsenoside-Rk

Ginsenoside-Rk

Ginsenoside-Rs;

Ginsenoside-Rs?
$\mathrm{R}_{1}$

$-\mathrm{H}$

-Gle-Glc

-Glc-Glc

-Glc-Glc

-Glc-Glc

-Glc-Glc

-Glc-Glc

-Glc-Glc

-Gle-Gilc

-Glc-Glc

-Gle

-Glc-Glc-Ac

-Gle-Glc-Ac

-Glc-Glc-Ac

$-\mathrm{H}$

$-\mathrm{H}$

$-\mathrm{H}$

$-\mathrm{H}$

$-\mathrm{H}$

$\begin{array}{ll}\mathrm{R}_{1} & \mathrm{R}_{2} \\ -\mathrm{H} & -\mathrm{H} \\ -\mathrm{H} & -\mathrm{OH} \\ -\mathrm{H} & -\mathrm{O}-\mathrm{Glc}-\mathrm{Rha} \\ - \text { Glc-Glc } & -\mathrm{H} \\ - \text { Glc } & -\mathrm{H} \\ -\mathrm{H} & -\mathrm{O}-\mathrm{Glc} \\ - \text { Glc-Glc-Ac } & -\mathrm{H} \\ -\mathrm{H} & -\mathrm{O}-\mathrm{Glc}-\mathrm{Ac}\end{array}$

$\mathrm{R}_{3}$

$-\mathrm{H}$

-Glc-Ara(pyr)-Xyl

-Glc-Ara(fur)-Xyl

-Glc-Glc-Xyl

-Gle-Glc

-Gle-Ara(pyr)

-Gle-Xyl

-Gle-Ara(fur)

-Gle

$-\mathrm{H}$

$-\mathrm{H}$

-Glc-Ara(pyr)

-Gle-Ara(fur)

$-\mathrm{H}$

$-\mathrm{H}$

-Glc

$-\mathrm{H}$

-Glc

$-\mathrm{H}$

$\begin{array}{ll}\text { O-Gle-Rha } & -\mathrm{H} \\ \text { O-Gle } & -\mathrm{H}\end{array}$

\begin{tabular}{|c|c|c|}
\hline & $\mathrm{R}_{1}$ & $\mathrm{R}_{2}$ \\
\hline DHPPD-II & $-\mathrm{H}$ & $-\mathrm{H}$ \\
\hline DHPPT-II & $-\mathrm{H}$ & $-\mathrm{OH}$ \\
\hline Ginsenoside-F4 & $-\mathrm{H}$ & -O-Glc-Rha \\
\hline Ginsenoside- $\mathrm{Rg}_{5}$ & -Glc-Gilc & $-\mathrm{H}$ \\
\hline Ginsenoside-Rh & -Glc & $-H$ \\
\hline Ginsenoside- $\mathrm{Rh}_{4}$ & $-\mathrm{H}$ & $-\mathrm{O}-\mathrm{Glc}$ \\
\hline Ginsenoside-Rs4 & -Glc-Glc-Ac & $-\mathrm{H}$ \\
\hline Ginsenoside-Rss & $-\mathrm{H}$ & $-\mathrm{O}-\mathrm{Glc}-\mathrm{Ac}$ \\
\hline
\end{tabular}

Fig. 1. Chemical structure of ginsenosides in Panax ginseng. PPD, protopanaxadiol; PPT, protopanaxatriol; DH, dehydro; Glc, glucose; Ara, abrabinose; Xyl, xylose; Rha, rhamnose; Ac, acetyl; pyr, pyranosyl; fur, furanosyl.

scribed for many serious symptoms. Ginseng is basically a tonic or adaptogenic herb that improves the basal level of health, body balance, and restoration capacity. Beyond its health-improving and self-healing functions, the pharmacological activities of ginseng span a broad range of protections to direct therapeutic effects on various organs and diseases. Because an enormous quantity of research has been conducted to uncover the biological activities of ginseng, all individual activities could not be listed in the limited space of this review. In this regard, the many reviews must serve as thorough guides to explore the pharmacology of ginseng [8,17-19].

Numerous compounds, from small molecules to macromolecules, have been isolated from and identified in ginseng, including triterpenesaponins, polyacetylenes, alkaloids, phenolics, polysaccharides, peptidoglycans, and proteins. Ginsenosides, the triterpene glycosides (saponins), are the unique and active constituents in ginseng. More than 100 ginsenosides have been isolated from all parts of the Panax species. Fig. 1 shows the 
structure of ginsenosides isolated from the $P$. ginseng, red ginseng, and sun ginseng. Protopanaxadiol and protopanaxatriol are the main structural features of the aglycone moiety of ginsenosides in $P$. ginseng. Excessive steaming results in modification of the ginsenoside structure, characterized by deglycosylation of the sugar moieties and double bond formation $\left(\Delta^{20(21)}\right.$ or $\left.\Delta^{20(22)}\right)$ following dehydroxylation at C20. Less polar ginsenosides with this aglycone structure are the unique and biologically active ingredients in red ginseng and sun ginseng [10]. Finally, polysaccharides are the other major and biologically interesting constituents in ginseng. Many polysaccharides, including panaxans, ginsenans, and pectins, have been isolated from ginseng and characterized. Ginseng polysaccharides show anti-diabetic, immune-modulating, anti-cancer, and anti-infection activities [20].

\section{ANALYTICAL METHODS}

Recent analytical methodologies are reviewed below on the basis of key techniques or analytical instrumentation. Most methods are separation-based tools, including TLC, HPTLC, HPLC, UPLC, GC, MS, capillary electrophoresis (CE), and counter current chromatography (CCC). Methods that do not rely on separation are also described, including metabolomic fingerprinting (metabolomics), genetic marker analysis, and immunoassays.

\section{Thin layer chromatography and high-performance thin layer chromatography}

TLC is a basic chromatography technique generally used for the quick identification or characterization of analytes. Because of its ease of use, versatility, high speed, and low cost, TLC is an excellent tool for the drug identification described in pharmacopoeias and is still used today in the pharmaceutical industry. Using uniform and fine coating materials ( $5 \mu \mathrm{m}$ of mean particle size), HPTLC yields higher separation, resolution, and reproducibility than conventional TLC. Moreover, a densitometric analysis of colored spots on TLC plates enables the quantitation of ginsenosides in crude or formulated ginseng preparations [21]. Recently, Reich et al. [22] validated an HPTLC method for the identification of botanical materials. This method is used for fingerprinting the ginsenoside composition in many Panax plants, including $P$. ginseng, $P$. quinquefolium, and $P$. notoginseng, and is useful as an official method in a current Good Manufacturing Practices environment.
High-performance liquid chromatography and ultra-performance liquid chromatography with hyphenated detection techniques

In ginseng analysis, HPLC is coupled with many different kinds of detectors, including UV detector, diode array detector (DAD or photodiode array detector), evaporative light scattering detector (ELSD), charged aerosol detector (CAD), pulsed amperometric detector (PAD), and MS [6,23]. Most MS applications will be discussed in a separate section.

HPLC is a highly favored and general method for ginseng analysis. It is versatile for most analytes, easy to use, accurate, and precise. Generally, most HPLC columns used for ginseng analysis are reversed-phase and packed in a standard 150 or $250 \times 4.6 \mathrm{~mm}$ column with $5 \mu \mathrm{m}$ silica beads that are covalently coated with $\mathrm{C}_{18}$ sorbents. Acetonitrile and buffered water are the typical solvent systems of choice for the mobile phase. Different stationary phases, including normal-phase, ion-exchange, and hydrophilic interacting materials, are also used for specific purposes $[6,7,23]$. Modified sorbents, such as polar end-capped materials or ultrafine sorbents less than 5 $\mu \mathrm{m}$ in size, are also available and present potential ways to improve HPLC analysis and applications.

Most HPLC applications in ginseng analysis over the past 5 years have involved the quantitation of ginsenosides or related projects [24]. Despite the frequent use of UV or DAD due to their ease of use or the ability to collect analytes after separation, these detectors have many weaknesses in ginsenoside analysis, as ginsenosides absorb UV rather poorly. UV detection of ginsenosides is usually performed at a short wavelength of 198 to $205 \mathrm{~nm}$, which creates a noisy baseline and limits the choice of solvents and modifiers. Photodiode array detectors, also called DADs, can provide real-time spectra from several wavelengths simultaneously. However, the sensitivity of a DAD is lower than that of a single wavelength UV detector that uses photomultiplier tubes to convert light into electrical signals. Using UV or DAD, ginsenosides have been determined from various Panax species and ginseng preparations [25-29]. Both UV and DAD could be easily connected to other types of detectors such as ELSD or MS. The simultaneous detection of UV-ELSD enabled the sensitive analysis of multiple components in natural medicine formulations containing ginseng, including UV- or ELSD-amenable [30,31]. Aside from ginsenosides, polyacetylenes have also been determined by UV detection in American ginseng roots $[25,27]$. Digitoxin and digoxin are useful internal standards in ginsenoside analysis with HPLC-DAD-MS or 
HPLC-ELSD [32,33]. A principal component analysis of data sets obtained from HPLC-DAD chromatograms is useful for distinguishing adulterations from different Panax plants in ginseng formulations [34]. In addition to ginseng saponin analysis, Qian et al. [35] used HPLCUV for the simultaneous determination of nucleosides in $P$. notoginseng using a multiple column switching technique.

ELSD is a promising alternative that could overcome the limitations of UV detection in ginsenoside analysis. The main problems of UV detection of ginsenosides are a noisy baseline and limited choice of solvents and modifiers due to the poor UV absorption by ginsenosides. ELSD is a universal and mass-selective detector for nonvolatile compounds that produces a stable baseline, even with gradient elution. Furthermore, many volatile mobile phase modifiers are available to obtain better resolution and selectivity $[6,23]$. Our research group was the first to use ELSD to quantify ginsenosides on an aminobonded column [36]. We also reported an optimized HPLC-ELSD method using a reversed-phase column for the determination of ginsenosides in white, red, and sun ginseng [11]. Since then, ELSD has been considered the standard choice for ginsenoside analysis. The HPLCELSD method has primarily been used for the simultaneous quantitation of various ginsenosides from Panax species or transformed ginseng preparations [33,37-40], and a principal component analysis of HPLC-ELSD chromatograms has been used to discriminate the geographic origins of $P$. ginseng roots [41]. Most ELSD analyses produce good chromatographic parameters, including high precision and accuracy, and the limit of detection (LOD) for ginsenosides has been determined at approximately $100 \mathrm{ng}[37,38]$.

CAD was developed as an alternative to ELSD to detect poor UV-responsive analytes. CAD is a mass-selective detector for non-volatile compounds, and its major advantages over ELSD are enhanced sensitivity and reproducibility. Using an HPLC-CAD system, Bai et al. [42] and Wang et al. [43] simultaneously quantified ginsenosides in $P$. ginseng and $P$. notoginseng. They found that $\mathrm{CAD}$ produced improved chromatographic parameters, including sensitivity, linearity and reproducibility, over UV and ELSD. The LOD and limit of quantitation (LOQ) for ginsenosides ranged from 0.01 to $0.15 \mu \mathrm{g}$ and 0.04 to $0.41 \mu \mathrm{g}$, respectively [42]. We anticipate that the use of CAD will continue to increase in the near future in ginseng analysis as an alternative to UV and ELSD.

PAD is a less popular HPLC detector in ginseng analysis. It is an electrochemical detector that measures the positive potential produced by sample oxidation on a gold electrode, lending itself to carbohydrate or polyalcohol quantitation coupled with high-performance anion-exchange chromatography (HPAEC). Our research group was the first to develop an ion chromatographyPAD method for ginsenoside analysis [44]. Joo et al. [45] simultaneously determined two Amadori compounds (arginyl-fructose and arginyl-fructosyl-glucose) in Korean red ginseng and plasma samples from rats treated with red ginseng extract using HPAEC-PAD. Finally, Kwon et al. [46] and Kwon et al. [47] developed a method for the highly sensitive quantitation of ginsenosides using reversed-phase HPLC-PAD under alkaline conditions. Their PAD method produced excellent linearity and improved LOD of less than $0.1 \mathrm{ng}$ for non-polar ginsenosides.

More recently, UPLC, an advanced type of HPLC, has emerged as a powerful tool in many analytical laboratories to profile phytochemicals in crude plant extracts [48]. UPLC uses short, narrow-bore columns packed with sorbents that is less than $2 \mu \mathrm{m}$ in size, thereby permitting faster analysis times and ultra-high resolution [6]. Existing HPLC conditions can be directly transferred to UPLC with only slight modifications. The UPLC-DAD method has been used for the rapid and simultaneous determination of saponins in Panax plants [49,50]. The LOQ and LOD (0.2-2.4 ng and 0.1-1.8 ng, respectively) were dramatically improved over the conventional HPLCDAD method. UPLC minimizes the running volumes of organic solvents as the mobile-phase, improving MS accessibility by minimizing the burden on the MS interfaces, that move ions from solution into the gas phase before entry into the MS. Dan et al. [51] and Xie et al. [52] developed an UPLC-electrospray (ESI)-MS method to determine saponins in $P$. notoginseng, and an UPLCtime-of-flight (TOF)-MS for metabolomics profiling of several Panax plants. Additional UPLC-MS applications will be discussed in the mass spectrometry section.

In addition to the aforementioned techniques, several other variations of LC methods have been reported. Rapid resolution LC with a short analytical column packed with ultrafine sorbents was used for the rapid and simultaneous determination of ginsenosides in Panax plants [53]. A radioactive tracer assay coupled with HPLC was used for the pharmacokinetic profiling of radioisotope labeled-ginsenoside Rd [54]. Using an HPLC system, Hu et al. [55] studied the retention behavior of ginsenosides on a reversed-phase stationary phase in varying conditions of solvent, $\mathrm{pH}$, ionic strength, and column temperature. Using hydrophilic interaction chromatog- 
raphy, Quiming et al. [56] studied a retention prediction model system for ginsenosides on a polyamine-bonded stationary phase. Using high-performance size exclusion chromatography and HPLC, Guan et al. [49] suggested a method for distinguishing polysaccharides in many natural medicines by saccharide mapping following the chromatographic analysis of enzymatic hydrolysates. Li et al. [57] developed an effective purification method for ginsenosides from ginseng preparations using $\mathrm{AB}-8$ macroporous adsorption chromatography, Amberlite IRA $900 \mathrm{CI}$ anion-exchange chromatography, and Aberlite XAD16 adsorption chromatography. Finally, Kuang et al. [58] developed a preparative purification procedure for ginsenoside Re from the ginseng bud using selective adsorption onto an activated carbon column.

As described above, HPLC and related chromatographic tools have been widely used in ginseng analysis. We anticipate that the HPLC method will continue to be improved upon and used in the future along with technological developments in analytical instrumentation and separation media.

\section{Gas chromatography with hyphenated detection techniques}

GC is a high-resolution and, environment friendly separation technique that avoids the use of toxic solvents. Its main disadvantage is its limited application to volatile compounds. Silylation (i.e., trimethylsilyl-derivatization) involves the substitution of the active hydrogen on a compound with an alkylsilyl group, such as a trimethylsilyl $\left(-\mathrm{SiMe}_{3}\right)$. Because the silylated derivatives are less polar, more volatile, and more thermally stable, they can be easily separated by gas chromatography and related techniques. Christensen summarized the silylation strategies for measuring ginsenoside content with $\mathrm{GC}$ after the hydrolytic conversion of ginsenosides to their corresponding aglycon [59]. Recently, Xie et al. [60] determined dencichine, a neurotoxic non-protein amino acid in Panax plants, using ethyl chloroformate derivatization followed by GC-MS.

Volatile compounds in ginseng have easily been determined by $\mathrm{GC}$ with applicable detection technologies, such as MS. Xie et al. [61] determined volatile oils (e.g., alpha-cadinol, alpha-bisabolol, thujopsene, and nhexadecanoic acid) in the root of $P$. ginseng at different ages. Abd El-Aty et al. [62] characterized volatile flavor compounds with GC-MS and determined their content in white and red ginseng. Finally, Liu et al. [63] determined polyacetylenes in Panax species using GC-MS method.

Another important application of GC is in the analysis of pesticides and their metabolites in ginseng samples. Pesticides are exogenous chemicals that are unavoidable in the cultivation of ginseng. Because the regulation of pesticides is different in different countries, pesticide profiling could provide critical clues in tracking the geographical origins of ginseng samples and involving safety issues for the consumption of ginseng preparations. GC has been coupled to several different detectors for the simultaneous quantitation of organohalogen and organophosphorous pesticides. While the electron capture detector and nitrogen-phosphorous detector are the classical detection techniques $[64,65]$, flame photometric detector and many types of MS detectors, including single/triple quadrupole and time-of-flight analyzer, are being used with automated sample handling systems [66,67]. New sample preparation techniques or isotope dilution method are also being studied with ginseng samples [68-70], and the official protocol for minimizing the inter-laboratory variation in pesticide profiling is still at the initial stage of consideration [71]. Additionally, HPLC has also been used for the simultaneous determination of pesticides [72].

\section{Mass spectrometry}

MS-based applications have occupied a major portion of ginseng analyses in recent years and are leading the trend in analytical methods. Because of its powerful identification and quantitation capabilities, MS is a versatile analyzer for the analysis of non-volatile molecules in ginseng, such as ginsenosides and their metabolites in biological systems $[6,7,23]$. MS is mostly used as a hyphenated detector coupled to chromatography instruments, such as HPLC, UPLC, and GC. Less common is direct sample analysis without separation using a direct insertion probe for volatile ginseng compounds or flow injection techniques for mass spectroscopic fingerprinting of Panax species [62,73]. As a liquid chromatography detector, an interface module with an ion source is generally used to evaporate solvents and convert sample molecules in the gas phase into ions or to move ions from the solution to the gas phase. Our group developed a thermospray LC-MS method for ginsenoside analysis [74]. However, the thermospray interface is currently used less frequently. Atmospheric pressure chemical ionization (APCI) and electrospray ionization (ESI) are typically used in ginseng analysis, with ESI being more common $[75,76]$. Electron impact (EI) ionization is the most commonly used GC-MS technique. While ESI and APCI are known as soft ionization methods that conserve the molecular ion, EI is a hard ionization technique that 
produces heavy fragmentation. Matrix-associated laser desorption/ionization is a soft ionization technique, allowing for the analysis of macromolecules such as biomolecules and organic polymers. It is used for the mass spectrometric imaging of ginsenoside localization in $P$. ginseng root [77].

Various types of mass analyzers are used for ginseng analysis: quadrupole (Q), ion trap (IT), TOF, and Fourier transform ion cyclotron resonance (FT-ICR) [6]. Moreover, multi-stage MS (also called tandem MS or MS/MS or $\mathrm{MS}^{\mathrm{n}}$ ) combines different mass analyzer designs that give advanced structural information, sensitivity, specificity, and versatility [6]. Triple quadrupole (QqQ), Q-IT, Q-TOF, or IT-TOF are used for ginseng analysis.

Quadrupole is the simplest and least expensive mass analyzer. Li et al. [78] and Li et al. [79] studied the pharmacokinetic profiles of $P$. notoginseng by determining multiple saponins in rat plasma simultaneously using HPLC-ESI-MS (single Q analyzer). The IT is an advantageous mass analyzer capable of single and multi-stage MS. Ginsenosides and its metabolites were characterized and determined by HPLC-MS (IT analyzer) [80,81]. TOF analyzer measures accurate mass with high resolution and a full-scan mass range, thereby making it suitable for the identification of unknown metabolites. However, a narrow linear range of quantification and expensive instrumentation are the main disadvantage of TOF compared to Q and IT analyzers. Chen et al. [80] developed a rapid and sensitive analytical assay to determine multiple bioactive constituents in ginseng preparations using LCESI-TOF. Most TOF analyzers are coupled to UPLC for ginseng analysis and are discussed in greater detail later. An FT-ICR, the most expensive mass analyzer, can be used as a multiple-stage MS similar to IT and also has a wide mass range and high mass resolution similar to TOF. Kong et al. [82] developed an HPLC-FT-ICR method for identifying the gastro-intestinal metabolite of ginsenosides in vitro.

HPLC-tandem MS applications have frequently been used to determine bioactive, new, or transformed phytochemical profile in many Panax plants or ginseng preparations [83-86]. They have also been used for the pharmacokinetic profiling of ginsenosides in biological systems [87-92]. HPLC-MS is also useful to study interactions between drugs and other herbal medicines with ginseng $[93,94]$. Both UV and mass profiles obtained by HPLC-DAD-MS analysis for chemical fingerprinting and quantitative analysis can be used for species authentication or quality control [95-97].

UPLC has drawn huge attention as a high-resolution chromatography system. Because UPLC provides high resolution and high accessibility to MS, it is generally used in MS-based metabolomics. Metabolomic studies of raw and steamed $P$. notogineng have employed UPLCTOF [68,98]. Dan et al. [51], Xie et al. [52], and Dan et al. [99] applied various MS systems, such as UPLCESI-TOF and UPLC-ESI-QqQ, for saponin and metabolite profiling in Panax plants. Pharmacokinetic studies have used UPLC-MS or tandem MS to simultaneously determine various ginsenosides [100,101]. In addition, UPCL/Q-TOF has been used for the rapid identification of adulterated ginseng preparations, chemical profiling of decoction-induced chemical transformation in ginseng preparations, and bioactive ginseng saponin identification [102-105].

\section{Capillary electrophoresis}

$\mathrm{CE}$, also known as capillary zone electrophoresis, can be used to separate electrically charged analytes based on their size-to-charge ratio in the interior of a small capillary filled with an electrolyte. Because most ginsenosides are neutral molecules, conventional CE could not separate them. However, modified CE techniques are used for ginsenoside analysis, such as micellar electrokinetic chromatography (MEKC) and microemulsion electrokinetic chromatography (MEEKC). Both MEKC and MEEKC can separate analytes by their differential partitioning between water-immiscible particulates (micelles and microemulsion) and a surrounding aqueous buffer solution.

Cao et al. [106] are the leading group developing $\mathrm{MEKC}$ and KEEKC methods for ginsenoside analysis. They developed and optimized an on-line injection technique for the analysis of neutral ginsenosides (ginsenoside $\mathrm{Rg}_{1}, \mathrm{Rf}, \mathrm{Rh}_{1}, \mathrm{Rd}, \mathrm{Rg}_{3}$, and notoginsenoside $\mathrm{R} 1$ ) with maximum stacking efficiency for good separation in MEEKC. They also developed a MEKC method with nonionic Brij-35 micelles that utilized on-line dual sweeping based on borate complexation and enhancement of the organic solvent field for the preconcentration of neutral ginsenosides [107]. Subsequently, they established a complex formation and acetonitrile sweeping technique for non-ionic MEEKC with UV detection for ginsenosides $\mathrm{Rf}, \mathrm{Rb}_{2}$ and Reusing a Brij-35 microemulsion [107].

\section{Counter current chromatography}

$\mathrm{CCC}$ is a liquid chromatography technique that separates solutes based on their partitioning between $2 \mathrm{im}$ miscible liquid phases, usually under centrifugal force. 
Advanced types of CCC with hyphenated detectors such as ELSD have been used in ginseng analysis: highperformance CCC, high-speed CCC, and centrifugal partition chromatography. These analytical instruments were primarily used for the preparative isolation or purification of selected ginsenosides, including ginsenoside $\mathrm{Rb}_{1}, \mathrm{Rd}$, Re, Rf, $\mathrm{Rg}_{1}, \mathrm{Rg}_{3}, \mathrm{Rg}_{5}, \mathrm{Rk}_{1}, \mathrm{~F} 4$, and notoginsenoside R1 [108-110].

\section{Metabolomic fingerprinting and metabolomics}

Conventionally, multivariate statistical analysis of spectral datasets has been used for the authentication or relevant grouping of plant species, rapid evaluation of composition, quality control, and metabolomics $[6,7]$. This section illustrates the rapid analytical methods used for ginseng without any separation procedures and the advanced statistics for data analysis.

NMR-based metabolomics are the most frequently used for ginseng analysis. These approaches are primarily aimed to discriminate ginseng samples by age, species, and cultivation area [111-115]. Lee et al. [116] suggested NMR-based metabolomics as a new quality assessment tool for ginseng. Major ginseng metabolites, including amino acids, have been identified as promising biomarkers for quality assurance in ginseng. NMR-based profiling is simple, comprehensive, and reproducible. However, low sensitivity for minor components remains a limitation of this method.

Infrared (IR) and Raman spectrometry are less frequently used for ginseng analysis relative to NMR. However, IR has been applied to species authentication and as a quality control in the industry. IR and Raman spectroscopy are simple and fast, but not applicable to quantitation. Most IR analyses have been used to generate spectroscopic ginseng datasets for ultimate metabolomics fingerprinting with multivariate statistical analysis. Yap et al. [117] established an IR-based fingerprinting method to detect and authenticate ginseng in many products [117]. They also suggested a "2-6PC rules" rapid and effective method for authenticating ginseng and discriminating between different Panax species [118]. In addition, Fourier transform infrared (FTIR) spectroscopy, 2D-FTIR and 2D-IR correlation spectroscopy, have been introduced for species identification, authentication, and the differentiation of age and cultivation origin [119-122].

Fourier transform Raman (FT-Raman) spectroscopy has alternatively been used for the same purpose as other fingerprinting techniques. Edwards et al. [123] achieved analytical discrimination of ginseng sources with FT-Raman spectroscopy. Chinese ginseng had unique Raman spectral features at $980 \mathrm{~cm}^{-1}$.

Other methods include light stable isotope analysis or strontium isotope analysis, which was used to differentiate between different geographical origins of ginseng $[124,125]$. The $\delta^{2} \mathrm{H}$ ratios were significantly different in ginsengs cultivated in Korea or China. Multivariate statistics are essential to fingerprinting techniques. Principal component analysis has been frequently used as a general statistical tool. Han et al. [126] suggested score-moment combined with linear discrimination analysis to improve discrimination efficiency. This method was well suited for the Raman spectroscopic discrimination of ginsengs cultivated in Korea and China.

\section{Genetic marker analysis}

A genetic marker is a gene or DNA sequence with a known location on a chromosome that could be used to identify a species. Genetic marker analysis has primarily been used to authenticate individual Panax species or cultivars, thereby contributing to the detection of specific ginsengs and detecting adulteration in commercial ginseng products.

Many genetic markers or tools have been examined in recent genetic analyses of ginseng. Genetic markers for ginseng include simple sequence repeats (also called microsatellites) [127,128], randomly amplified polymorphic DNA [129], restriction fragment length polymorphisms $[130,131]$, insertion/deletion markers [132], single nucleotide polymorphisms (SNPs) [132], amplified fragment length polymorphisms (AFLPs) [133], AFLP-derived sequence characterized amplified regions [134], and cleaved amplified polymorphic sequence markers [135]. Novel genetic tools to discover markers have also been developed including loop-mediated isothermal amplification [136] and DNA microarray-based fingerprinting $[137,138]$.

Sathiyamoorthy et al. [139] and Wang et al. [140] performed a transcriptomic analysis of ginseng roots to study the expressed sequence tags putatively involved in the ginsenoside biosynthetic pathway and stress resistance. Their results may contribute to the genetic engineering of ginseng plants, such as the development of stress-resistant and ginsenoside-rich plants. They also discovered new genetic targets for determining the new ginseng cultivar "Chunpoong", such as a major latexlike protein gene [132], mitochondrial nad7 intron 4 region [141], and mitochondrial cytochrome oxidase subunit 2 intron I/II regions [142]. Together, they suggested the molecular identification of the ginseng cultivar "Gumpoong" based on 26S rDNA analysis [143], and 
"Chunpoong" or "Yunpoong" cultivars based on real-time PCR-based SNP marker analysis [144-146]. Analysis of SNP markers may contribute to the molecular authentication of $P$. ginseng and products [147]. More recently, Zuo et al. [148] presented a DNA barcoding method for the identification of diverse Panax species and clusters through the combinatorial analysis of both the PSBATRNH (encodes photosystem II protein D1-tRNA ${ }^{\mathrm{His}}$ ) noncoding region and the internal transcribed spacer region. Genetic marker analysis provides direct evidence for species authentication, the identification of adulteration, and genetic information regarding specific bioactive component biosynthetic pathways [149-152]. Along with the development of molecular biotechnology, innovative genetic tools will likely provide promising options for the identification of ginseng species at the DNA level.

\section{Immunoassay}

Immunoassays utilize the specific reaction between an antibody and its antigen for qualitative or quantitative analysis. Recent immunoassays used in ginseng analysis include the enzyme-linked immunosorbent assay (ELISA), immunoblotting, and immunofluorescence. ELISA is a specific and accurate quantitation assay in which the antibody is conjugated to an enzyme, such as horseradish peroxidase. Pongkitwitoon et al. [153] and Sritularak et al. [154] used a monoclonal antibody against specific ginsenosides for the ELISA-based determination of ginsenoside $\mathrm{Rb}_{1}, \mathrm{Rg}_{1}$, and $\mathrm{Re}$ in American ginseng berries and flowers $[153,154]$. The development of antibodies targeting ginsenoside has also contributed to the preparation of knockout extracts using immunoaffinity chromatography $[155,156]$. Meanwhile, Morinaga and Shoyama [157] and Tanaka et al. [158] developed a new immunoblotting method called "Eastern blotting". Ginsenosides, pre-separated on a silica gel TLC plate, were transferred to a polyvinylidene fluoride membrane that was treated with $\mathrm{NaIO}_{4}$, which was then treated with bovine serum albumin (BSA) to form a ginsenoside-BSA conjugate. A monoclonal antibody targeting aglycon of ginsenoside was used for immunodetection. Quantitation was performed by image-based analysis of color density, following immunodetection and corresponding substrate treatment. This "Eastern blotting" method was used to determine ginsenoside $\mathrm{Rb}_{1}, \mathrm{Rg}_{1}$, and $\mathrm{Re}$ with monoclonal antibodies targeting each ginsenoside $[158,159]$. Moreover, the localization of ginsenoside $\mathrm{Rb}_{1}$ in the various parts of $P$. ginseng was monitored by immunofluorescence with a monoclonal antibody targeting ginsenoside $\mathrm{Rb}_{1}$ [160].

\section{CONCLUSION}

Ginseng has served as a model not only for testing the performance of various analytical techniques but also for developing novel analytical methods to characterize natural medicines. Recent methodologies employed in ginseng analysis range from single/multiple component quantitation to fingerprinting or metabolomics with statistical analysis. Chromatography with hyphenated detection, mainly HPLC, has still been the primary method of ginseng analysis. UPLC with analytical column technology enables fast separation and high resolution. Sophisticated MS instrumentation guarantees ultra-high accuracy, precision, and sensitivity. Advanced multivariate analysis has also accelerated the development of informatics and metabolomics. Biochemical approaches, such as immunoassays and genetic marker analyses, are being used with increasing frequency in ginseng analysis and are likely to contribute more significantly in the future. Relevant technical advances may help in understanding the Panax species, thereby contributing to the creation of beneficial bioengineered species. The major applications of ginseng analysis are in species authentication, quality control, pharmacokinetic profiling, and biomarker identification in biological systems. A comprehensive understanding of individual approaches and accumulated applications in the laboratory and clinics may provide promising insights for further development of ginseng analysis.

\section{REFERENCES}

1. Koehn FE, Carter GT. The evolving role of natural products in drug discovery. Nat Rev Drug Discov 2005;4:206220.

2. Li JW, Vederas JC. Drug discovery and natural products: end of an era or an endless frontier? Science 2009;325: 161-165.

3. Li W, Mak M, Jiang H, Wang Q, Pang Y, Chen K, Han Y. Novel anti-Alzheimer's dimer Bis(7)-cognitin: cellular and molecular mechanisms of neuroprotection through multiple targets. Neurotherapeutics 2009;6:187-201.

4. Jiang Y, David B, Tu P, Barbin Y. Recent analytical approaches in quality control of traditional Chinese medicines--a review. Anal Chim Acta 2010;657:9-18.

5. Li SP, Zhao J, Yang B. Strategies for quality control of Chinese medicines. J Pharm Biomed Anal 2011;55:802809.

6. Qi LW, Wang CZ, Yuan CS. Isolation and analysis of ginseng: advances and challenges. Nat Prod Rep 
2011;28:467-495.

7. Angelova N, Kong HW, van der Heijden R, Yang SY, Choi YH, Kim HK, Wang M, Hankemeier T, van der Greef J, Xu G et al. Recent methodology in the phytochemical analysis of ginseng. Phytochem Anal 2008;19:216

8. Kiefer D, Pantuso T. Panax ginseng. Am Fam Physician 2003;68:1539-1542.

9. Chang WT, Choi YH, Van der Heijden R, Lee MS, Lin MK, Kong H, Kim HK, Verpoorte R, Hankemeier T, Van der Greef J et al. Traditional processing strongly affects metabolite composition by hydrolysis in Rehmannia glutinosa roots. Chem Pharm Bull (Tokyo) 2011;59:546-552.

10. Kim WY, Kim JM, Han SB, Lee SK, Kim ND, Park MK, Kim CK, Park JH. Steaming of ginseng at high temperature enhances biological activity. J Nat Prod 2000;63: 1702-1704.

11. Kwon SW, Han SB, Park IH, Kim JM, Park MK, Park JH. Liquid chromatographic determination of less polar ginsenosides in processed ginseng. J Chromatogr A 2001;921:335-339.

12. Sun S, Qi LW, Du GJ, Mehendale SR, Wang CZ, Yuan CS. Red notoginseng: higher ginsenoside content and stronger anticancer potential than Asian and American ginseng. Food Chem 2011;125:1299-1305.

13. Yun BS, Lee MR, Oh CJ, Cho JH, Wang CY, Gu LJ, Mo EK, Sung CK. Characterization of black ginseng extract with acetyl- and butyrylcholinesterase inhibitory and antioxidant activities. J Ginseng Res 2010;34:348-354.

14. Yoon SR, Lee GD, Kim HK, Kwon JH. Monitoring of chemical changes in explosively puffed ginseng and the optimization of puffing conditions. J Ginseng Res 2010;34:59-67.

15. Choi K, Choi C. Proapoptotic ginsenosides compound K and Rh enhance Fas-induced cell death of human astrocytoma cells through distinct apoptotic signaling pathways. Cancer Res Treat 2009;41:36-44.

16. Kim MH, Hong HD, Kim YC, Rhee YK, Kim KT, Rho J. Ginsenoside changes in red ginseng manufactured by acid impregnation treatment. J Ginseng Res 2010;34:93-97.

17. Helms S. Cancer prevention and therapeutics: Panax ginseng. Altern Med Rev 2004;9:259-274.

18. Ernst E. Panax ginseng: an overview of the clinical evidence. J Ginseng Res 2010;34:259-263.

19. Yuan CS, Wang CZ, Wicks SM, Qi LW. Chemical and pharmacological studies of saponins with a focus on American ginseng. J Ginseng Res 2010;34:160-167.

20. Baek SH, Lee JG, Park SY, Bae ON, Kim DH, Park JH. Pectic polysaccharides from Panax ginseng as the antirotavirus principals in ginseng. Biomacromolecules
2010;11:2044-2052.

21. Vanhaelen-Fastre RJ, Faes ML, Vanhaelen MH. Highperformance thin-layer chromatographic determination of six major ginsenosides in Panax ginseng. J Chromatogr A 2000;868:269-276.

22. Reich E, Schibli A, DeBatt A. Validation of high-performance thin-layer chromatographic methods for the identification of botanicals in a cGMP environment. J AOAC Int 2008;91:13-20.

23. Fuzzati N. Analysis methods of ginsenosides. J Chromatogr B Analyt Technol Biomed Life Sci 2004;812:119133.

24. Kim YK, Yoo DS, Xu H, Park NI, Kim HH, Choi JE, Park SU. Ginsenoside content of berries and roots of three typical Korean ginseng (Panax ginseng) cultivars. Nat Prod Commun 2009;4:903-906.

25. Christensen LP, Jensen M. Biomass and content of ginsenosides and polyacetylenes in American ginseng roots can be increased without affecting the profile of bioactive compounds. J Nat Med 2009;63:159-168.

26. Gao X, Dan M, Zhao A, Xie G, Jia W. Simultaneous determination of saponins in flower buds of Panax notoginseng using high performance liquid chromatography. Biomed Chromatogr 2008;22:244-249.

27. Wang JR, Leung CY, Ho HM, Chai S, Yau LF, Zhao ZZ, Jiang ZH. Quantitative comparison of ginsenosides and polyacetylenes in wild and cultivated American ginseng. Chem Biodivers 2010;7:975-983.

28. Wei YJ, Li SL, Li P. Simultaneous determination of seven active components of Fufang Danshen tablet by high performance liquid chromatography. Biomed Chromatogr 2007;21:1-9.

29. Yoon SR, Lee GD, Park JH, Lee IS, Kwon JH. Ginsenoside composition and antiproliferative activities of explosively puffed ginseng (Panax ginseng C.A. Meyer). J Food Sci 2010;75:C378-C382.

30. Wei YJ, Qi LW, Li P, Luo HW, Yi L, Sheng LH. Improved quality control method for Fufang Danshen preparations through simultaneous determination of phenolic acids, saponins and diterpenoid quinones by HPLC coupled with diode array and evaporative light scattering detectors. J Pharm Biomed Anal 2007;45:775-784.

31. Zhao J, Wang D, Duan S, Wang J, Bai J, Li W. Analysis of fuzhisan and quantitation of baicalin and ginsenoside Rb(1) by HPLC-DAD-ELSD. Arch Pharm Res 2009;32:989-996.

32. Balsevich JJ, Bishop GG, Deibert LK. Use of digitoxin and digoxin as internal standards in HPLC analysis of triterpene saponin-containing extracts. Phytochem Anal 2009;20:38-49 
33. Kim SN, Ha YW, Shin H, Son SH, Wu SJ, Kim YS. Simultaneous quantification of 14 ginsenosides in Panax ginseng C.A. Meyer (Korean red ginseng) by HPLCELSD and its application to quality control. J Pharm Biomed Anal 2007;45:164-170.

34. Wang CZ, Ni M, Sun S, Li XL, He H, Mehendale SR, Yuan CS. Detection of adulteration of notoginseng root extract with other Panax species by quantitative HPLC coupled with PCA. J Agric Food Chem 2009;57:23632367.

35. Qian ZM, Wan JB, Zhang QW, Li SP. Simultaneous determination of nucleobases, nucleosides and saponins in Panax notoginseng using multiple columns high performance liquid chromatography. J Pharm Biomed Anal 2008;48:1361-1367.

36. Park MK, Park JH, Han SB, Shin YG, Park IH. Highperformance liquid chromatographic analysis of ginseng saponins using evaporative light scattering detection. J Chromatogr A 1996;736:77-81.

37. Qu C, Bai Y, Jin X, Wang Y, Zhang K, You J, Zhang H. Study on ginsenosides in different parts and ages of Panax quinquefolius L. Food Chem 2009;115:340-346.

38. Sun BS, Gu LJ, Fang ZM, Wang CY, Wang Z, Lee MR, Li Z, Li JJ, Sung CK. Simultaneous quantification of 19 ginsenosides in black ginseng developed from Panax ginseng by HPLC-ELSD. J Pharm Biomed Anal 2009;50:1522.

39. Wan JB, Li SP, Chen JM, Wang YT. Chemical characteristics of three medicinal plants of the Panax genus determined by HPLC-ELSD. J Sep Sci 2007;30:825-832.

40. Zhang X, Ma X, Si B, Zhao Y. Simultaneous determination of five active hydrolysis ingredients from Panax quinquefolium L. by HPLC-ELSD. Biomed Chromatogr 2011;25:646-651.

41. Lee DY, Cho JG, Lee MK, Lee JW, Lee YH, Yang DC, Baek NI. Discrimination of Panax ginseng roots cultivated in different areas in Korea using HPLC-ELSD and principal component analysis. J Ginseng Res 2011;35:3138.

42. Bai CC, Han SY, Chai XY, Jiang Y, Li P, Tu PF. Sensitive determination of saponins in Radix et Rhizoma Notoginseng by charged aerosol detector coupled with HPLC. J Liq Chromatogr Relat Technol 2009;32:242-260.

43. Wang L, He WS, Yan HX, Jiang Y, Bi KS, Tu PF. Performance evaluation of charged aerosol and evaporative light scattering detection for the determination of ginsenosides by LC. Chromatographia 2009;70:603-608.

44. Park MK, Park JH, Lee MY, Kim SJ, Park IJ. Microanalysis of ginseng saponins by ion chromatography with pulsed amperometric detection. J Liq Chromatogr
1994;17:1171-1181.

45. Joo KM, Park CW, Jeong HJ, Lee SJ, Chang IS. Simultaneous determination of two Amadori compounds in Korean red ginseng (Panax ginseng) extracts and rat plasma by high-performance anion-exchange chromatography with pulsed amperometric detection. J Chromatogr B Analyt Technol Biomed Life Sci 2008;865:159-166.

46. Kwon HJ, Jeong JS, Lee YM, Hong SP. A reversed-phase high-performance liquid chromatography method with pulsed amperometric detection for the determination of glycosides. J Chromatogr A 2008;1185:251-257.

47. Kwon HJ, Jeong JS, Sim HJ, Lee YM, Kim YS, Hong SP. Sensitive high-performance liquid chromatography method of non-polar ginsenosides by alkalineenhanced pulsed amperometric detection. J Chromatogr A 2009;1216:4445-4450.

48. Eugster PJ, Guillarme D, Rudaz S, Veuthey JL, Carrupt PA, Wolfender JL. Ultra high pressure liquid chromatography for crude plant extract profiling. J AOAC Int 2011; 94:51-70.

49. Guan J, Lai CM, Li SP. A rapid method for the simultaneous determination of 11 saponins in Panax notoginseng using ultra performance liquid chromatography. J Pharm Biomed Anal 2007;44:996-1000.

50. Zhang CY, Dong L, Wang J, Chen SL. Simultaneous determination of ten ginsenosides in panacis quinquefolii radix by ultra performance liquid chromatography and quality evaluation based on chemometric methods. Pharmazie 2011;66:553-559.

51. Dan M, Su M, Gao X, Zhao T, Zhao A, Xie G, Qiu Y, Zhou M, Liu Z, Jia W. Metabolite profiling of Panax notoginseng using UPLC-ESI-MS. Phytochemistry 2008;69:2237-2244.

52. Xie G, Plumb R, Su M, Xu Z, Zhao A, Qiu M, Long X, Liu Z, Jia W. Ultra-performance LC/TOF MS analysis of medicinal Panax herbs for metabolomic research. J Sep Sci 2008;31:1015-1026.

53. Ma J, Ma YC, Wang D, Hou FF, Luo M, Lu S, Gorecki DC, Patel AV. Simultaneous quantification of Panax and Epimedium species using Rapid Resolution Liquid Chromatography (RRLC). Nat Prod Commun 2011;6:581-586.

54. Sun D, Wang B, Shi M, Zhang YX, Zhou LF, Liu ZR, Wu ZL, Jiang W, Han JL, Xiong LZ et al. Pharmacokinetic, tissue distribution and excretion of ginsenoside-Rd in rodents. Phytomedicine 2012;19:369-373.

55. Hu P, Luo GA, Wang Q, Zhao ZZ, Wang W, Jiang ZH. The retention behavior of ginsenosides in HPLC and its application to quality assessment of radix ginseng. Arch Pharm Res 2009;32:667-676.

56. Quiming NS, Denola NL, Saito Y, Jinno K. Multiple lin- 
ear regression and artificial neural network retention prediction models for ginsenosides on a polyamine-bonded stationary phase in hydrophilic interaction chromatography. J Sep Sci 2008;31:1550-1563.

57. Li H, Lee JH, Ha JM. Effective purification of ginsenosides from cultured wild ginseng roots,red ginseng, and white ginseng with macroporous resins. J Microbiol Biotechnol 2008;18:1789-1791.

58. Kuang P, Wang G, Yuan Q, Liang H. Separation and purification of ginsenoside Re from ginseng bud by selective adsorption of active carbon and preparative high-performance liquid chromatography. Nat Prod Res 2012;26:286-290.

59. Christensen LP. Ginsenosides chemistry, biosynthesis, analysis, and potential health effects. Adv Food Nutr Res 2009;55:1-99.

60. Xie GX, Qiu YP, Qiu MF, Gao XF, Liu YM, Jia W. Analysis of dencichine in Panax notoginseng by gas chromatography-mass spectrometry with ethyl chloroformate derivatization. J Pharm Biomed Anal 2007;43:920-925.

61. Qiu Y, Lu X, Pang T, Ma C, Li X, Xu G. Determination of radix ginseng volatile oils at different ages by comprehensive two-dimensional gas chromatography/time-offlight mass spectrometry. J Sep Sci 2008;31:3451-3457.

62. Abd El-Aty AM, Kim IK, Kim MR, Lee C, Shim JH. Determination of volatile organic compounds generated from fresh, white and red Panax ginseng (C. A. Meyer) using a direct sample injection technique. Biomed Chromatogr 2008;22:556-562.

63. Liu JH, Lee CS, Leung KM, Yan ZK, Shen BH, Zhao ZZ, Jiang ZH. Quantification of two polyacetylenes in Radix ginseng and roots of related Panax species using a gas chromatography-mass spectrometric method. J Agric Food Chem 2007;55:8830-8835.

64. Park YS, Abd El-Aty AM, Choi JH, Cho SK, Shin DH, Shim JH. Pesticide multiresidue analysis in Panax ginseng (C. A. Meyer) by solid-phase extraction and gas chromatography with electron capture and nitrogenphosphorus detection. Biomed Chromatogr 2007;21:2939.

65. Wu J, Liu Y, Zhao R, Xu R. Fast pesticide multiresidue analysis in American ginseng (Panax quinquefolium L.) by gas chromatography with electron capture detection. J Nat Med 2011;65:406-409.

66. Hayward DG, Wong JW. Organohalogen and organophosphorous pesticide method for ginseng root: a comparison of gas chromatography-single quadrupole mass spectrometry with high resolution time-of-flight mass spectrometry. Anal Chem 2009;81:5716-5723.

67. Wong JW, Hennessy MK, Hayward DG, Krynitsky AJ,
Cassias I, Schenck FJ. Analysis of organophosphorus pesticides in dried ground ginseng root by capillary gas chromatography-mass spectrometry and -flame photometric detection. J Agric Food Chem 2007;55:1117-1128.

68. Chan EC, Yap SL, Lau AJ, Leow PC, Toh DF, Koh HL. Ultra-performance liquid chromatography/time-offlight mass spectrometry based metabolomics of raw and steamed Panax notoginseng. Rapid Commun Mass Spectrom 2007;21:519-528.

69. Wong JW, Zhang K, Tech K, Hayward DG, Krynitsky AJ, Cassias I, Schenck FJ, Banerjee K, Dasgupta S, Brown D. Multiresidue pesticide analysis of ginseng powders using acetonitrile- or acetone-based extraction, solidphase extraction cleanup, and gas chromatography-mass spectrometry/selective ion monitoring (GC-MS/SIM) or -tandem mass spectrometry (GC-MS/MS). J Agric Food Chem 2010;58:5884-5896.

70. Wong YC, Wong SK, Kam TT. Preparation of reference material for organochlorine pesticides in a herbal matrix. Anal Bioanal Chem 2008;392:1507-1513.

71. Kong MF, Chan S, Wong YC, Wong SK, Sin DW. Interlaboratory comparison for the determination of five residual organochlorine pesticides in ginseng root samples by gas chromatography. J AOAC Int 2007;90:1133-1141.

72. Jia Z, Mao X, Chen K, Wang K, Ji S. Comprehensive multiresidue method for the simultaneous determination of 74 pesticides and metabolites in traditional Chinese herbal medicines by accelerated solvent extraction with high-performance liquid chromatography/tandem mass spectrometry. J AOAC Int 2010;93:1570-1588.

73. Chen P, Harnly JM, Harrington Pde B. Flow injection mass spectroscopic fingerprinting and multivariate analysis for differentiation of three Panax species. J AOAC Int 2011;94:90-99.

74. Park MK, Park JH, Hwang GS, Lee MY, Park IJ. Analysis of ginsenosides by thermospray LC/MS. Korean J Ginseng Sci 1995; 19:134-137.

75. Ding L, Luo X, Tang FL, Nie L, Yao S. To improve the quantification sensitivity of large molecular weight compounds: with ginsenosides as example. Rapid Commun Mass Spectrom 2007;21:989-996.

76. Leung KS, Chan K, Bensoussan A, Munroe MJ. Application of atmospheric pressure chemical ionisation mass spectrometry in the identification and differentiation of Panax species. Phytochem Anal 2007;18:146-150.

77. Taira S, Ikeda R, Yokota N, Osaka I, Sakamoto M, Kato M, Sahashi Y. Mass spectrometric imaging of ginsenosides localization in Panax ginseng root. Am J Chin Med 2010;38:485-493.

78. Li X, Sun J, Wang G, Hao H, Liang Y, Zheng Y, Yan 
B, Sheng L. Simultaneous determination of Panax notoginsenoside $\mathrm{R} 1$, ginsenoside $\mathrm{Rg}_{1}, \mathrm{Rd}, \mathrm{Re}$ and $\mathrm{Rb}_{1}$ in rat plasma by HPLC/ESI/MS: platform for the pharmacokinetic evaluation of total Panax notoginsenoside, a typical kind of multiple constituent traditional Chinese medicine. Biomed Chromatogr 2007;21:735-746.

79. Li X, Wang G, Sun J, Hao H, Xiong Y, Yan B, Zheng Y, Sheng L. Pharmacokinetic and absolute bioavailability study of total Panax notoginsenoside, a typical multiple constituent traditional chinese medicine (TCM) in rats. Biol Pharm Bull 2007;30:847-851.

80. Chen G, Yang M, Song Y, Lu Z, Zhang J, Huang H, Guan $\mathrm{S}, \mathrm{Wu}$ L, Guo DA. Comparative analysis on microbial and rat metabolism of ginsenoside $\mathrm{Rb}_{1}$ by high-performance liquid chromatography coupled with tandem mass spectrometry. Biomed Chromatogr 2008;22:779-785.

81. Qian ZM, Lu J, Gao QP, Li SP. Rapid method for simultaneous determination of flavonoid, saponins and polyacetylenes in folium ginseng and radix ginseng by pressurized liquid extraction and high-performance liquid chromatography coupled with diode array detection and mass spectrometry. J Chromatogr A 2009;1216:38253830 .

82. Kong H, Wang M, Venema K, Maathuis A, van der Heijden R, van der Greef J, Xu G, Hankemeier T. Bioconversion of red ginseng saponins in the gastro-intestinal tract in vitro model studied by high-performance liquid chromatography-high resolution Fourier transform ion cyclotron resonance mass spectrometry. J Chromatogr A 2009;1216:2195-2203.

83. Chan HH, Hwang TL, Reddy MV, Li DT, Qian K, Bastow KF, Lee KH, Wu TS. Bioactive constituents from the roots of Panax japonicus var. major and development of a LC-MS/MS method for distinguishing between natural and artifactual compounds. J Nat Prod 2011;74:796-802.

84. Chen W, Dang Y, Zhu C. Simultaneous determination of three major bioactive saponins of Panax notoginseng using liquid chromatography-tandem mass spectrometry and a pharmacokinetic study. Chin Med 2010;5:12.

85. Liu Y, Li J, He J, Abliz Z, Qu J, Yu S, Ma S, Liu J, Du D. Identification of new trace triterpenoid saponins from the roots of Panax notoginseng by high-performance liquid chromatography coupled with electrospray ionization tandem mass spectrometry. Rapid Commun Mass Spectrom 2009;23:667-679.

86. Zhang X, Song F, Cui M, Liu Z, Liu S. Investigation of the hydrolysis of ginsenosides by high performance liquid chromatography-electrospray ionization mass spectrometry. Planta Med 2007;73:1225-1229.

87. Ruan JQ, Leong WI, Yan R, Wang YT. Characterization of metabolism and in vitro permeability study of notoginsenoside R1 from Radix notoginseng. J Agric Food Chem 2010;58:5770-5776.

88. Song M, Zhang S, Xu X, Hang T, Jia L. Simultaneous determination of three Panax notoginseng saponins at subnanograms by LC-MS/MS in dog plasma for pharmacokinetics of compound Danshen tablets. J Chromatogr B Analyt Technol Biomed Life Sci 2010;878:3331-3337.

89. Yan B, Wang G, A J, Xie L, Hao H, Liang Y, Sun J, Li X, Zheng Y. Construction of the fingerprints of ginseng stem and leaf saponin reference substances and spiked plasma sample by LC-ESI/MS and its application to analyzing the compounds absorbed into blood after oral administration of ginseng stem and leaf saponin in rat. Biol Pharm Bull 2007;30:1657-1662.

90. Yan Z, Zhu ZL, Wang HQ, Li W, Mi YX, Liu CX. Pharmacokinetics of Panaxatrol disuccinate sodium, a novel anti-cancer drug from Panax notoginseng, in healthy volunteers and patients with advanced solid tumors. Acta Pharmacol Sin 2010;31:1515-1522.

91. Yang L, Xu S, Liu C, Su Z. In vivo metabolism study of ginsenoside $\mathrm{Re}$ in rat using high-performance liquid chromatography coupled with tandem mass spectrometry. Anal Bioanal Chem 2009;395:1441-1451.

92. Yang L, Xu SJ, Wu ZF, Liu YM, Zeng X. Determination of ginsenoside- $\operatorname{Rg}(1)$ in human plasma and its application to pharmacokinetic studies following intravenous administration of 'Shenmai' injection. Phytother Res 2009;23:65-71.

93. Wang W, Liao QP, Quan LH, Liu CY, Chang Q, Liu XM, Liao YH. The effect of Acorus gramineus on the bioavailabilities and brain concentrations of ginsenosides $\mathrm{Rg}_{1}$, $\mathrm{Re}$ and $\mathrm{Rb}_{1}$ after oral administration of Kai-Xin-San preparations in rats. J Ethnopharmacol 2010;131:313-320.

94. Zhang R, Jie J, Zhou Y, Cao Z, Li W. Long-term effects of Panax ginseng on disposition of fexofenadine in rats in vivo. Am J Chin Med 2009;37:657-667.

95. Sun J, Chen P. Differentiation of Panax quinquefolius grown in the USA and China using LC/MS-based chromatographic fingerprinting and chemometric approaches. Anal Bioanal Chem 2011;399:1877-1889.

96. Yao H, Shi P, Shao Q, Fan X. Chemical fingerprinting and quantitative analysis of a Panax notoginseng preparation using HPLC-UV and HPLC-MS. Chin Med 2011;6:9.

97. Yunfei L, Haibin Q, Yiyu C. Identification of major constituents in the traditional Chinese medicine "QI-SHENYI-QI" dropping pill by high-performance liquid chromatography coupled with diode array detection-electrospray ionization tandem mass spectrometry. J Pharm Biomed Anal 2008;47:407-412. 
98. Toh DF, New LS, Koh HL, Chan EC. Ultra-high performance liquid chromatography/time-of-flight mass spectrometry (UHPLC/TOFMS) for time-dependent profiling of raw and steamed Panax notoginseng. J Pharm Biomed Anal 2010;52:43-50.

99. Dan M, Xie G, Gao X, Long X, Su M, Zhao A, Zhao T, Zhou M, Qiu Y, Jia W. A rapid ultra-performance liquid chromatography-electrospray Ionisation mass spectrometric method for the analysis of saponins in the adventitious roots of Panax notoginseng. Phytochem Anal 2009;20:6876.

100. Deng GF, Wang DL, Meng MX, Hu F, Yao TW. Simultaneous determination of notoginsenoside R1, ginsenoside $\mathrm{Rg}_{1}, \mathrm{Re}, \mathrm{Rb}_{1}$ and icariin in rat plasma by ultra-performance liquid chromatography-tandem mass spectrometry. J Chromatogr B Analyt Technol Biomed Life Sci 2009;877:2113-2122.

101. Joo KM, Lee JH, Jeon HY, Park CW, Hong DK, Jeong HJ, Lee SJ, Lee SY, Lim KM. Pharmacokinetic study of ginsenoside Re with pure ginsenoside Re and ginseng berry extracts in mouse using ultra performance liquid chromatography/mass spectrometric method. J Pharm Biomed Anal 2010;51:278-283.

102. Kim N, Kim K, Choi BY, Lee D, Shin YS, Bang KH, Cha SW, Lee JW, Choi HK, Jang DS et al. Metabolomic approach for age discrimination of Panax ginseng using UPLC-Q-Tof MS. J Agric Food Chem 2011;59:1043510441.

103. Li L, Luo GA, Liang QL, Hu P, Wang YM. Rapid qualitative and quantitative analyses of Asian ginseng in adulterated American ginseng preparations by UPLC/Q-TOFMS. J Pharm Biomed Anal 2010;52:66-72.

104. Li SL, Lai SF, Song JZ, Qiao CF, Liu X, Zhou Y, Cai H, Cai BC, Xu HX. Decocting-induced chemical transformations and global quality of Du-Shen-Tang, the decoction of ginseng evaluated by UPLC-Q-TOF-MS/MS based chemical profiling approach. J Pharm Biomed Anal 2010;53:946-957.

105. Mao Q, Yang J, Cui XM, Li JJ, Qi YT, Zhang PH, Wang Q. Target separation of a new anti-tumor saponin and metabolic profiling of leaves of Panax notoginseng by liquid chromatography with eletrospray ionization quadrupole time-of-flight mass spectrometry. J Pharm Biomed Anal 2012;59:67-77.

106. Cao J, Qi LW, Chen J, Li P. Pressure and electrokinetic injections for on-line sample stacking neutral analytes in microemulsion electrokinetic chromatography with saltcontaining matrixes. Electrophoresis 2008;29:4422-4430.

107. Cao J, Li B, Chang YX, Li P. Direct on-line analysis of neutral analytes by dual sweeping via complexation and organic solvent field enhancement in nonionic MEKC. Electrophoresis 2009;30:1372-1379.

108. Ha YW, Lim SS, Ha IJ, Na YC, Seo JJ, Shin H, Son SH, Kim YS. Preparative isolation of four ginsenosides from Korean red ginseng (steam-treated Panax ginseng C. A. Meyer), by high-speed counter-current chromatography coupled with evaporative light scattering detection. J Chromatogr A 2007;1151:37-44.

109. Qi X, Ignatova S, Luo G, Liang Q, Jun FW, Wang Y, Sutherland I. Preparative isolation and purification of ginsenosides $\mathrm{Rf}, \mathrm{Re}, \mathrm{Rd}$ and $\mathrm{Rb}_{1}$ from the roots of Panax ginseng with a salt/containing solvent system and flow step-gradient by high performance counter-current chromatography coupled with an evaporative light scattering detector. J Chromatogr A 2010;1217:1995-2001.

110. Wang J, Liu CM, Li L, Bai HL. Isolation of four highpurity dammarane saponins from extract of Panax notoginseng by centrifugal partition chromatography coupled with evaporative light scattering detection in one operation. Phytochem Anal 2011;22:263-267.

111. Kang J, Lee S, Kang S, Kwon HN, Park JH, Kwon SW, Park S. NMR-based metabolomics approach for the differentiation of ginseng (Panax ginseng) roots from different origins. Arch Pharm Res 2008;31:330-336.

112. Kim SH, Hyun SH, Yang SO, Choi HK, Lee BY. (1)HNMR-based discrimination of thermal and vinegar treated ginseng roots. J Food Sci 2010;75:C577-C581.

113. Lin WN, Lu HY, Lee MS, Yang SY, Chen HJ, Chang YS, Chang WT. Evaluation of the cultivation age of dried ginseng radix and its commercial products by using (1)HNMR fingerprint analysis. Am J Chin Med 2010;38:205218.

114. Shin YS, Bang KH, In DS, Kim OT, Hyun DY, Ahn IO, $\mathrm{Ku} \mathrm{BC}$, Kim SW, Seong NS, Cha SW et al. Fingerprinting analysis of fresh ginseng roots of different ages using 1H-NMR spectroscopy and principal components analysis. Arch Pharm Res 2007;30:1625-1628.

115. Yang SO, Shin YS, Hyun SH, Cho S, Bang KH, Lee D, Choi SP, Choi HK. NMR-based metabolic profiling and differentiation of ginseng roots according to cultivation ages. J Pharm Biomed Anal 2012;58:19-26.

116. Lee EJ, Shaykhutdinov R, Weljie AM, Vogel HJ, Facchini PJ, Park SU, Kim YK, Yang TJ. Quality assessment of ginseng by (1)H NMR metabolite fingerprinting and profiling analysis. J Agric Food Chem 2009;57:75137522.

117. Yap KY, Chan SY, Lim CS. Authentication of traditional Chinese medicine using infrared spectroscopy: distinguishing between ginseng and its morphological fakes. J Biomed Sci 2007; 14:265-273. 
118. Yap KY, Lai TK, Chan SY, Lim CS. Infrared authentication of ginseng species: the use of the 2-6PC rule. J AOAC Int 2009;92:672-679.

119. Jin XJ, Zhang Y, Xie YF, Cong Q, Zhao B. Analysis of infrared spectroscopy of ginsengs by support vector machine and wavelet transform. Guang $\mathrm{Pu}$ Xue Yu Guang Pu Fen Xi 2009;29:656-660.

120. Liu D, Li YG, Xu H, Sun SQ, Wang ZT. Differentiation of the root of cultivated ginseng, mountain cultivated ginseng and mountain wild ginseng using FT-IR and twodimensional correlation IR spectroscopy. J Mol Struct 2008;883-884:228-235.

121. Lu GH, Zhou Q, Sun SQ, Leung KS, Zhang H, Zhao ZZ. Differentiation of Asian ginseng, American ginseng and Notoginseng by Fourier transform infrared spectroscopy combined with two-dimensional correlation infrared spectroscopy. J Mol Struct 2008;883:91-98.

122. Zhang YL, Chen JB, Lei Y, Zhou Q, Sun SQ, Noda I. Evaluation of different grades of ginseng using Fouriertransform infrared and two-dimensional infrared correlation spectroscopy. J Mol Struct 2010;974:94-102.

123. Edwards HG, Munshi T, Page K. Analytical discrimination between sources of ginseng using Raman spectroscopy. Anal Bioanal Chem 2007;389:2203-2215.

124. Horacek M, Min JS, Heo SC, Soja G. Discrimination between ginseng from Korea and China by light stable isotope analysis. Anal Chim Acta 2010;682:77-81.

125. Lee AR, Gautam M, Kim J, Shin WJ, Choi MS, Bong YS, Hwang GS, Lee KS. A multianalytical approach for determining the geographical origin of ginseng using strontium isotopes, multielements, and 1H NMR analysis. J Agric Food Chem 2011;59:8560-8567.

126. Han J, Chung H, Han SH, Yoon MY. Score-moment combined linear discrimination analysis (SMCLDA) as an improved discrimination method. Analyst 2007; 132:67-74

127. Kim J, Jo BH, Lee KL, Yoon ES, Ryu GH, Chung KW. Identification of new microsatellite markers in Panax ginseng. Mol Cells 2007;24:60-68.

128. Liu H, Xia T, Zuo YJ, Chen ZJ, Zhou SL. Development and characterization of microsatellite markers for Panax notoginseng (Araliaceae), a Chinese traditional herb. Am J Bot 2011;98:e274- e276.

129. Lim W, Mudge KW, Weston LA. Utilization of RAPD markers to assess genetic diversity of wild populations of North American ginseng (Panax quinquefolium). Planta Med 2007;73:71-76.

130. Diao Y, Lin XM, Liao CL, Tang CZ, Chen ZJ, Hu ZL. Authentication of Panax ginseng from its adulterants by PCR-RFLP and ARMS. Planta Med 2009;75:557-560.
131. Serrone PD, Attorri L, Palazzino G. Easy DNA extraction for rapid detection of Panax ginseng C. A. Meyer in commercial ginseng products. Nat Prod Res 2007;21:1099-1103.

132. Sun H, Wang HT, Kwon WS, In JG, Lee BS, Yang DC. Development of molecular markers for the determination of the new cultivar 'Chunpoong' in Panax ginseng C. A. Meyer associated with a major latex-like protein gene. Biol Pharm Bull 2010;33:183-187.

133. Zhuravlev YN, Reunova GD, Kats IL, Muzarok TI, Bondar AA. Genetic variability and population structure of endangered Panax ginseng in the Russian Primorye. Chin Med 2010;5:21.

134. Choi YE, Ahn CH, Kim BB, Yoon ES. Development of species specific AFLP-derived SCAR marker for authentication of Panax japonicus C. A. Meyer. Biol Pharm Bull 2008;31:135-138.

135. Lee JW, Bang KH, Kim YC, Seo AY, Jo IH, Lee JH, Kim OT, Hyun DY, Cha SW, Cho JH. CAPS markers using mitochondrial consensus primers for molecular identification of Panax species and Korean ginseng cultivars (Panax ginseng C. A. Meyer). Mol Biol Rep 2012;39:729-736.

136. Sasaki Y, Komatsu K, Nagumo S. Rapid detection of Panax ginseng by loop-mediated isothermal amplification and its application to authentication of ginseng. Biol Pharm Bull 2008;31:1806-1808.

137. Niu L, Mantri N, Li CG, Xue C, Wohlmuth H, Pang EC. Detection of Panax quinquefolius in Panax ginseng using 'subtracted diversity array'. J Sci Food Agric 2011;91:1310-1315.

138. Zhu S, Fushimi H, Komatsu K. Development of a DNA microarray for authentication of ginseng drugs based on 18S rRNA gene sequence. J Agric Food Chem 2008;56:3953-3959.

139. Sathiyamoorthy S, In JG, Gayathri S, Kim YJ, Yang DC. Generation and gene ontology based analysis of expressed sequence tags (EST) from a Panax ginseng C. A. Meyer roots. Mol Biol Rep 2010;37:3465-3472.

140. Sathiyamoorthy S, In JG, Lee BS, Kwon WS, Yang DU, Kim JH, Yang DC. Insilico analysis for expressed sequence tags from embryogenic callus and flower buds of Panax ginseng C. A. Meyer. J Ginseng Res 2011;35:2130.

141. Wang H, Sun H, Kwon WS, Jin H, Yang DC. Molecular identification of the Korean ginseng cultivar "Chunpoong" using the mitochondrial nad7 intron 4 region. Mitochondrial DNA 2009;20:41-45.

142. Wang H, Sun H, Kwon WS, Jin H, Yang DC. A PCRbased SNP marker for specific authentication of Korean 
ginseng (Panax ginseng) cultivar "Chunpoong”. Mol Biol Rep 2010;37:1053-1057.

143. Wang H, Sun H, Kwon WS, Jin H, Yang DC. A simplified method for identifying the Panax ginseng cultivar Gumpoong based on 26S rDNA. Planta Med 2010;76:399-401.

144. Sun H, Lee OR, Kim YJ, Jeong SK, In JG, Kwon WS, Kim SY, Yang DC. Identification of 'Chunpoong' among Panax ginseng cultivars using real time PCR and SNP marker. J Ginseng Res 2010;34:47-50.

145. Sun H, Wang HT, Kwon WS, Kim YJ, In JG, Yang DC. A simple and rapid technique for the authentication of the ginseng cultivar, Yunpoong, using an SNP marker in a large sample of ginseng leaves. Gene 2011;487:75-79.

146. Wang H, Kwon WS, Yang DU, Kim MK, Sathiyamoorthy S, Jin H, Yang DC. Development of a multiplex amplification refractory mutation system for simultaneous authentication of Korean ginseng cultivars "Gumpoong" and "Chungsun". Mitochondrial DNA 2011;22:35-38.

147. Wang H, Kim MK, Kwon WS, Jin H, Liang Z, Yang DC. Molecular authentication of Panax ginseng and ginseng products using robust SNP markers in ribosomal external transcribed spacer region. J Pharm Biomed Anal 2011;55:972-976.

148. Zuo Y, Chen Z, Kondo K, Funamoto T, Wen J, Zhou S. DNA barcoding of Panax species. Planta Med 2011;77:182-187.

149. Chen S, Luo H, Li Y, Sun Y, Wu Q, Niu Y, Song J, Lv A, Zhu Y, Sun C et al. 454 EST analysis detects genes putatively involved in ginsenoside biosynthesis in Panax ginseng. Plant Cell Rep 2011;30:1593-1601.

150. In JG, Kim MK, Lee OR, Kim YJ, Lee BS, Kim SY, Kwon WS, Yang DC. Molecular identification of Korean mountain ginseng using an amplification refractory mutation system (ARMS). J Ginseng Res 2010;34:41-46.

151. Kim TD, Han JY, Huh GH, Choi YE. Expression and functional characterization of three squalene synthase genes associated with saponin biosynthesis in Panax gin- seng. Plant Cell Physiol 2011;52:125-137.

152. Kwon KR, Park WP, Kang WM, Jeon EY, Jang JH. Identification and analysis of differentially expressed genes in mountain cultivated ginseng and mountain wild ginseng. J Acupunct Meridian Stud 2011;4:123-128.

153. Pongkitwitoon B, Sakamoto S, Morinaga O, Juengwatanatrakul T, Shoyama Y, Tanaka H, Morimoto S. Single-chain variable fragment antibody against ginsenoside Re as an effective tool for the determination of ginsenosides in various ginsengs. J Nat Med 2011;65:24-30.

154. Sritularak B, Morinaga O, Yuan CS, Shoyama Y, Tanaka $\mathrm{H}$. Quantitative analysis of ginsenosides $\mathrm{Rb}_{1}, \mathrm{Rg}_{1}$, and $\mathrm{Re}$ in American ginseng berry and flower samples by ELISA using monoclonal antibodies. J Nat Med 2009;63:360363.

155. Uto T, Tuvshintogtokh I, Shoyama Y. Preparation of knockout extract for determination of really active compound using MAb. Curr Drug Discov Technol 2011;8:1623.

156. Yuan CS, Tanaka H. Bioactivity of American ginseng by knockout extract preparation using monoclonal antibody. Curr Drug Discov Technol 2011;8:32-41.

157. Morinaga O, Shoyama Y. Development of new staining technology "eastern blotting" using monoclonal antibody. Curr Drug Discov Technol 2011;8:42-50.

158. Tanaka H, Fukuda N, Shoyama Y. Eastern blotting and immunoaffinity concentration using monoclonal antibody for ginseng saponins in the field of traditional chinese medicines. J Agric Food Chem 2007;55:3783-3787.

159. Morinaga O, Uto T, Yuan CS, Tanaka H, Shoyama Y. Evaluation of a new eastern blotting technique for the analysis of ginsenoside Re in American ginseng berry pulp extracts. Fitoterapia 2010;81:284-288.

160. Yokota S, Onohara Y, Shoyama Y. Immunofluorescence and immunoelectron microscopic localization of medicinal substance, $\mathrm{Rb}_{1}$, in several plant parts of Panax ginseng. Curr Drug Discov Technol 2011;8:51-59. 